\title{
SOME UNUSUAL MANIFESTATIONS OF THYROID DISEASE
}

\author{
By W. R. TRotTer, D.M., M.R.C.P.
}

From the Medical Unit, University Colleg. Hospital Medical School

In this article I have tried to describe three rather unusual aspects of thyroid disease which happen to have interested me during the past ten years or so. The three subjects I have chosenadult cretinism, drug goitres and localized myxoedema - are not related to one another.

\section{Cretinism in Adolescents and Adults}

In medical teaching, emphasis is rightly given to the diagnosis of cretinism during the first year or two of life. This is the all-important period, for correct diagnosis and treatment at this stage will largely determine whether the infant grows up to be a normal human being or a hopeless idiot. Nevertheless, not all cretins are detected at an early age, particularly if the defect is incomplete; and of those that are, not all receive continuous replacement therapy throughout the growing period. All too often medication is haphazard or forgotten altogether for long periods. One may therefore be confronted with an adolescent, or even an adult, with signs of incomplete cretinism, presenting with a clinical picture which is rather different from that seen in the infant on the one hand, and in myxoedema developing in adult life on the other. It seems worth noting the salient features of undetected or incompletely treated cretinism, before going on to discuss some of the rarer causes of this condition.

The most constant defect shown by cretins is in skeletal development, which may be grossly defective even when intellectual progress is not far from normal. This shows clearly in their infantile proportions. The most striking feature is the shortness of the legs relative to the trunk. This may be demonstrated by the simple expedient of measuring the distance from crown to pubis, and pubis to heel. In the normal adolescent, the length of the trunk will equal or exceed the length of the legs. In cretins, not only are the legs short in proportion to the trunk, but the thighs are also short in relation to the legs as a whole (Fig. I). These proportions are merely those of the normal infant, which in cretins are preserved into adolescence or even adult life. Naturally these measure-

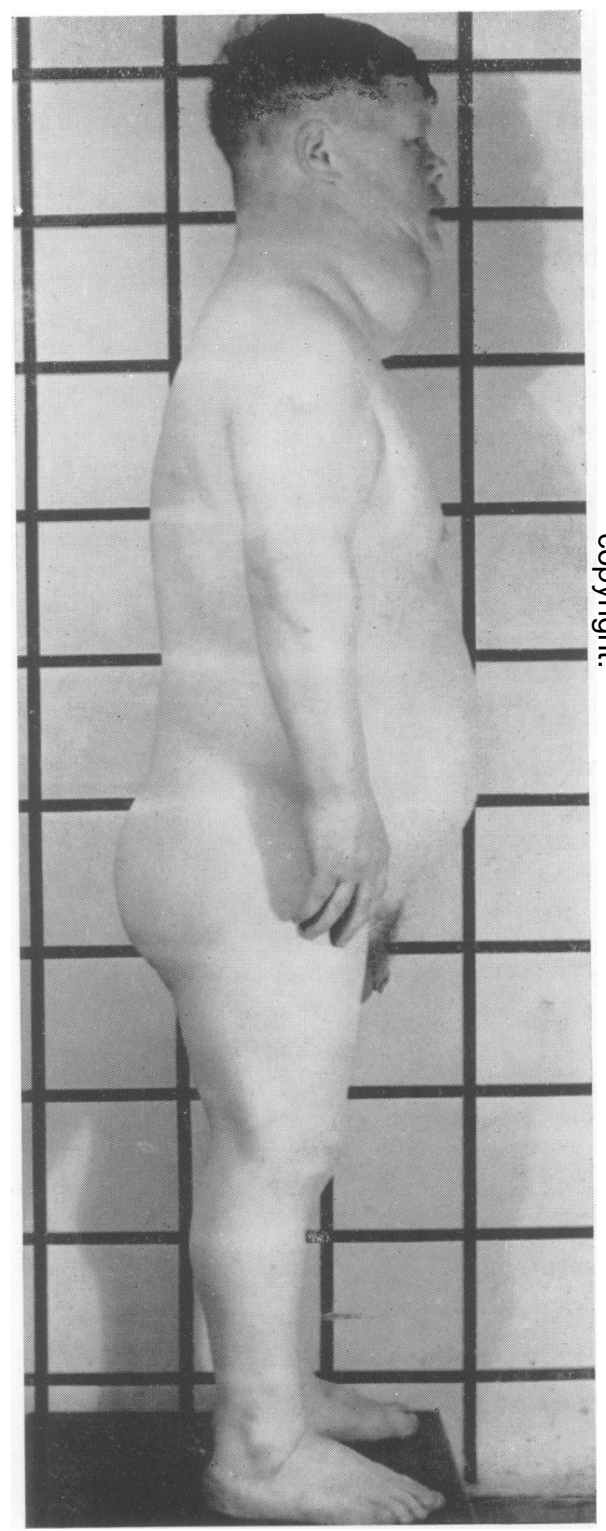

FIG. I.-A goitrous cretin, aged 44 . 
ments do not assist in the diagnosis of cretinism in infants.

Other than direct measurement of thyroid function, the most profitable investigations are X-ray studies of the skeleton. Particular attention should be paid to the epiphyses, the development of which is markedly affected by the lack of thyroid hormone. These studies enable an estimate of bone age to be made, which in a cretin is always considerably less than the chronological age. In addition there are often striking changes in the head of the femur, which is fragmented and distorted in a manner very similar to that seen in Perthes' disease (though it may be remarked in parentheses that true cases of Perthes' disease have normally functioning thyroids). The destructive changes in the femoral heads cause a waddling gait.

Although other features of hypothyroidism, such as puffy face, thick lips, large tongue and dry skin may be present, they are not constant. Nor is mental retardation necessarily a marked feature. It is quite possible for the intellectual development of a cretin to reach the lower limits of the normal range, although skeletal development is grossly retarded.

In most cretins enlargement of the pituitary fossa is evident in the X-ray. This can be regarded as a confirmation of the diagnosis, and should not be misinterpreted (as was done in one of our cases) as an indication of a pituitary tumour. It is merely an indication of the increased production of T.S.H. by the pituitary in hypothyroid states.

\section{Some Causes of Cretinism}

Cretinism is commonly divided into two types: the endemic form, due to severe iodine-deficiency, and the sporadic, in which it is usually supposed that the thyroid has failed to develop. The endemic cretin often has a goitre, but the sporadic cretin, as defined above, obviously cannot have one. Nevertheless, goitrous cretins have been encountered from time to time, in areas where there is no reason to suspect iodine deficiency, and it has become clear in recent years that several distinct types of thyroid failure can occur.

Mainly as a result of studies by J. B. Stanbury and his colleagues, no less than three types of congenital biochemical abnormalities of the thyroid have been defined in cases of goitrous cretinism. In the first of these (Stanbury and Hedge, 1950) the thyroid is unable to convert iodides into organic iodine compounds; in the second, (Stanbury et al., 1955a), it can form iodotyrosines, but cannot conjugate them to form the active hormones, thyroxine and triiodothyronine; while in the third, hormone synthesis can probably occur normally, but excess iodotyrosine molecules (released by enzymic hydrolysis of thyroglobulin) cannot be broken down and are in fact excreted in the urine (Stanbury et al., 1955b). This results in a considerable drain of iodine from the body and hence a state of iodine deficiency. The primary defect of the third group has been shown by Querido, Stanbury et al., (1956) to be a lack of the deiodinase which is normally present in the thyroid and other tissues.

Although the reported cases have been few there has usually been evidence of a familial incidence. Hutchison and McGirr (1953, 1956) have studied a remarkable family of itinerant tinkers encountered in the Scottish Lowlands, of which no less than ten members had goitres and hypothyroidism. Recent studies on some members of this family suggest that they fall into the third category of biochemical defect, i.e. they lack the enzyme which deiodinates iodotyrosines. Genetic studies indicate that in this family the defect is determined by the activity of a single autosomal recessive gene.

I have only encountered one case of goitrous cretinism (Fig. I). Unfortunately he was an orphan and hence no genetic studies were possible; and at the time he was seen, techniques for defining the type of boichemical defect had not been worked out. He was 44 and had spent most of his life in an institution for mental defectives. Nevertheless? he could write quite well and his I.Q. on the pers formance scale of the Wechsler-Bellevue intelo ligence test was 75, a rating considered to indicate only borderline defectiveness. As can be seen in the figure, the goitre was of huge proportions, so the greater part of it was removed and he was treated with thyroxine.

In another type of cretinism the defect is embryological, rather than boichemical. The foetal thyroid becomes arrested in the base of the tongue during the early stages of its journey from the foramen caecum to its normal post-natal position. If it can manage to grow in this situation hypothyroidism does not occur, but the patient may present at a later date with a fleshy mid-line lump protruding from the base of the tongue-the classical 'lingual thyroid.' But if the abnormally situated thyroid cannot expand to its normal size (perhaps because too deeply embedded in the tongue muscles) cretinism will develop, but no tumour will be visible. We have had two cases of this type, and others have been described by McGirr and Hutchison (1955). In our cases the lingual thyroid was too small to be seen or felt (in one it was estimated to weigh no more than one gram), and could only be located by directional counting after a tracer dose of radio-iodine (Fig. 2). Uptake by the tiny gland was not much below normal ( 17 per cent. of the dose at 24 hours) in the first case, but subsequently iodine was leaving it at 


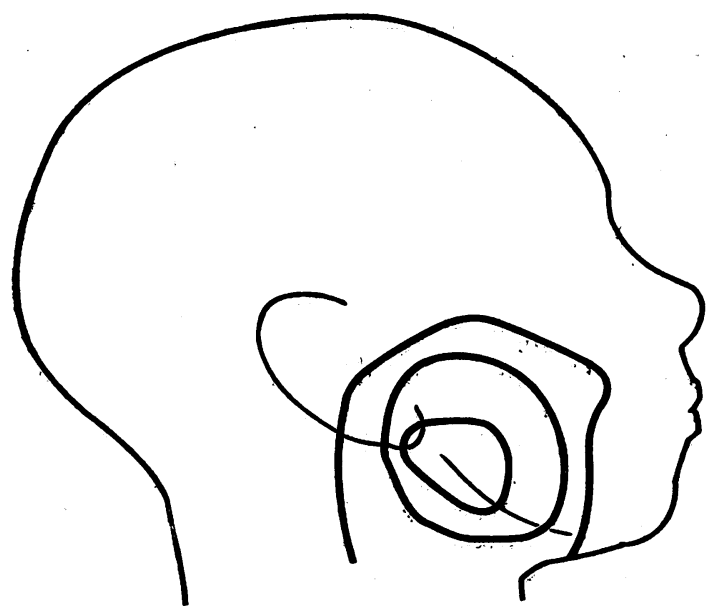

Fig. 2.- Outline of the lateral aspect of the head and neck of a cretin, aged 17 . 'The 'contour lines' indicate the counting-rates observed with a highly collimated scintillation counter at 48 hours after a tracer dose of radio-iodine. The Kighest countingrate was opposite the angle of the jaw, and shows that the thyroid was situated in the base of the tongue.

an abnormally high rate ( 5 per cent. per day). This indicated that what little thyroid tissue there was was hyperfunctioning, presumably as a result of over-secretion of T.S.H. for the pituitary fossa was enlarged. A considerable excess of T.S.H. in the serum of this case was demonstrated by Gilliland and Strudwick (1956), (Case 21). The findings in the second case were almost identical except that the uptake by the gland was much smaller ( 3 per cent. of the dose). The patients were aged 17 and 40 respectively and had not previously been diagnosed as cretins. In both the body proportions were typical of this condition, and the femoral heads showed characteristic changes. Both were of low normal intellect, and able to earn a living, the one as a machinist in a factory, the other as a kitchen porter. Both have improved considerably with thyroxine treatment, the boy of 17 having increased his height by 8 inches in three years.

\section{Drug-induced Goitre and Myxoedema}

In 1936, M. H. Barker noted the occurrence of goitre in three patients with hypertension who were being treated with thiocyanates; and two of the three also showed signs of hypothyroidism. In a further communication (I94I) he recorded I I goitres among 246 patients treated with thiocyanates; nine of the patients showed myxoedematous facial changes and had B.M.R.s in the region of - 10 per cent. The signs of hypothyroidism, and the goitres, disappeared when the patients were given thyroid extract. These early obser vations illustrated the characteristic feature of drug-induced goitre, namely that it is usually accompanied by at least partial hypothyroidism $c$ Similarly, the characteristic feature of drug induced myxoedema is that it is usually accom-s? panied by a goitre. There are exceptions to botke these rules, but they are relatively few. Hence whenever a patient is seen who has both goitre ands indications of hypothyroidism he should immedi- $-\frac{\pi}{\Omega}$ ately be asked whether he has been taking anyo sort of medicines or tablets regularly during the period of development of the goitre. The only? other common cause of goitre with hypothyroidism is Hashimoto's thyroiditis (lymphadenoid goitre) ${ }^{\omega}$ and specific tests for the diagnosis of this conditiong are now becoming available.

Thiocyanates are no longer used for the treat-w. ment of hypertension, and so this cause of goitre $\omega$ has now been eliminated. It was of theoreticapo interest because the action of thiocyanates on thei thyroid differs from that of most other drugs. Thiocyanates prevent the thyroid from concen-o trating inorganic iodide, but do not prevent the oxidation and organic binding of iodine. The practical effect of this difference is that thiocyanate induced goitre is the only one that can be entirely $y_{0}$ prevented by the administration of relatively smâlu doses of iodide.

When patients with angina or congestive cardiagico failure are treated with thiouracil or related compounds, in an attempt to reduce the metabolico load, myxoedema of course occurs. Usually, buto not invariably, a goitre develops also. Thiso illustrates the point that a goitre represents an $\overrightarrow{\overrightarrow{0}}$ attempt to overcome a biochemical obstacle to the 3 manufacture of thyroid hormone, of whatever nature. In some elderly subjects this compensatory effort does not take place. The same mechan-o ism-mediated by the anterior pituitary-is alsoseen at work in patients with thyrotoxicosis whos have been overtreated with anti-thyroid drugs. Under these conditions their goitres enlarge fur-o ther; this response constitutes one of the arguments for believing that the anterior pituitary functions normally in cases of thyrotoxicosis.

Goitre, often with hypothyroidism, has been produced unintentionally by a variety of sub- $N^{\circ}$ stances which do not necessarily bear any chemical relation to one another. This diversity of chemicalo structure should lead us to suspect that the list of active substances is probably far from complete 0 and that more anti-thyroid substances will be disto covered by ordinary clinical observation. One condition is however essential for a drug to cause? goitre; it must be taken continuously for a period of at least several months. This condition rules? out many drugs which are given for only short $\stackrel{\mathbb{\rho}}{\overparen{D}}$ 
periods and in fact demands also a, somewhat obsessional type of patient, who will actually take every single dose as prescribed. The thyroid is an organ whose enzyme mechanisms are easily thrown out of gear, and which is particularly vulnerable in that its raw material-iodine-is relatively scarce and therefore the gland is compelled to work at a high efficiency. On the other hand it is provided with a very large storage capacity, so that even if the manufacture of hormone is virtually stopped, the supplies in a normal human thyroid will last for some two to three months.

In I95० Bull and Fraser described three cases of goitre with hypothyroidism, which could be attributed to the application of resorcinol ointment to varicose ulcers. The goitre and hypothyroidism cleared up when the ointment was withheld. This is the only type of drug-induced goitre on record, in which the drug was not taken by mouth. Indeed, it is probable that resorcinol would only have an anti-thyroid effect if applied in this way, since it is so rapidly excreted. Doniach and Logothetopoulos (1953) for instance, found that single injections of resorcinol to rats had an inhibiting effect on the uptake of radio-iodine which persisted for only three hours. To demonstrate the production of goitre by resorcinol in rats they had to use other devices to slow down its absorption into the bloodstream.

At the present time by far the commonest form of drug-induced goitre is that which occurs in patients with tuberculosis who are being treated with para-amino salicylic acid (P.A.S.). Although only a minority of patients so treated develop goitre, the probable explanation is that only a minority of patients actually take P.A.S. in the doses prescribed for them. The chest physician should welcome the appearance of goitre in his P.A.S.-treated cases, for it is an indication that he is dealing with a conscientious patient! The goitre can readily be controlled by giving small doses of thyroxine along with the P.A.S. The anti-thyroid effect of P.A.S. has been shown by Edwards, Rowlands and Trotter (1954) to be very similar to that of thiouracil. The technique used to demonstrate this point was as follows: about an hour after a dose of P.A.S. the subject was given a tracer dose of radio-iodine. The counting-rate opposite the neck and thigh were recorded one hour later, and the subject immediately drank a solution containing $400 \mathrm{mg}$. of potassium perchlorate. Counts were then made at ro minute intervals opposite the neck and thigh. A proportion of the thigh count was subtracted from the neck count to allow for the extra-thyroid radioactivity in the neck tissues. If the patient had been taking P.A.S., the thyroid count fell rapidly after perchlorate, levelling out after about 40 minutes. The proportion of the radio-iodine still remaining in the thyroid at this time varied from 25 to 95 per cent. of that initially present, and indicated the completeness or otherwise of the block to the organic binding of iodine. A similar result after the administration of iodopyrine is illustrated in Fig. 3 .

The same technique was applied by Morgans and Trotter (1955), to a patient who developed a goitre while under treatment with phenyl butazone for rheumatoid arthritis. A similar discharge of radio-iodine from the thyroid was observed after perchlorate, so long as the patient was taking the drug. When phenyl butazone was stopped, perchlorate no longer caused a discharge of radioiodine. This technique should be a useful one to apply whenever it is suspected that a goitre is due to the action of a drug. It should, however, be pointed out that the presence of a goitre with indications of hypothyroidism is also found in Hashimoto's thyroiditis; and in that condition also perchlorate is capable of discharging radio-iodine from the thyroid (Morgans and Trotter, in the press). It is therefore necessary to repeat the test after the drug has been discontinued, before one can be certain that it was the cause of the goitre.

Cobalt salts, which are used in the treatment of certain anaemias, are also known to cause goitre (Kriss et al., 1955). It is very probable that othero goitrogenic drugs are also employed in medicine, but have not yet been recognized. There is an opportunity here for simple clinical observation, aided where facilities are available by studies with radio-iodine and perchlorate.

Finally, there is the odd observation that an excessive intake of jodides may occasionally cause both goitre and myxoedema (Morgans and Trotter, 1953). This is a paradoxical phenomenon, for of course iodine is required for the manufacture of thyroid hormones. In our two cases the uptake of radio-iodine, shortly after stopping the intake of iodide, was temporarily very high, indicating that the thyroid had become hyperplastic. But there is no apparent reason why only a small minority of all those patients who take iodides regularly should develop goitre and myxoederna. Possibly these people have an underlying thyroid lesion, not sufficient in itself to cause clinical manifestations. This appears to have been the case in the patient described by Hydrovitz and Rose (1956) in which goitre and myxoedema developed while he was taking iodopyrine. We have seen a striking case of congenital goitre, in a child whose mother had been taking large doses of iodopyrine during pregnancy as treatment for her asthma. The mother herself had a goitre, but it has not been possible to determine what part iodopyrine played in its 


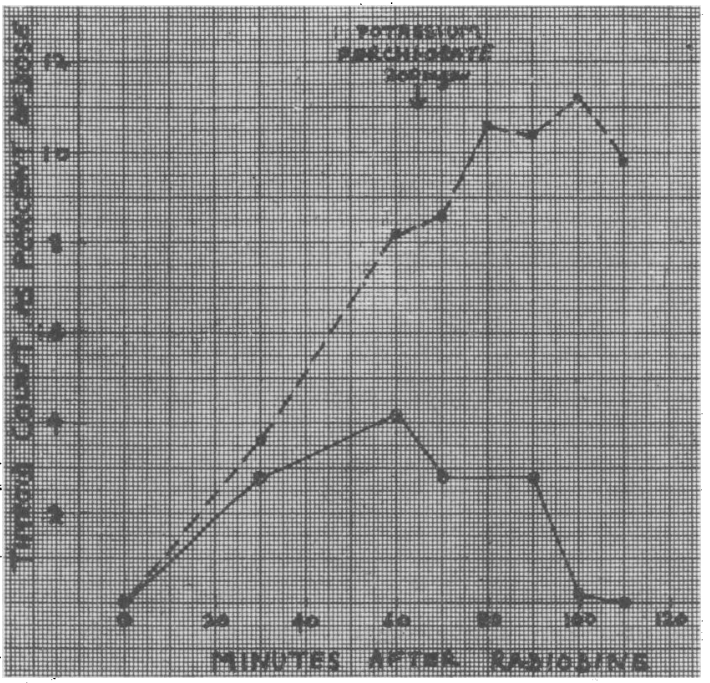

FIG. 3.-Thyroid counting-rate after two separate tracer doses of radio-iodine given to a euthyroid subject. Interrupted line; no previous medication. Continuous line; $30 \mathrm{mg}$. of iodopyrine given 5 minutes before the radio-iodine: $200 \mathrm{mg}$. of potassium perchlorate was given at $\mathbf{6 5}$ minutes after radioiodine in both instances; when it followed iodopyrine the thyroid radio-activity was discharged, showing that it had not been organically bound.

aetiology, because we have not been able to persuade her to refrain from taking the drug for long enough to observe the effect on the size of the thyroid. It was, however, possible to show that the uptake of radio-iodine by her thyroid was markedly depressed by iodopyrine (but not by the other constituents of her asthma powders). The same technique, as was used in the studies on P.A.S. and phenyl butazone revealed that in normal subjects after single doses of iodopyrine, much of the radio-iodine in the thyroid was dischargeable by perchlorate (Fig. 3). It is uncertain whether this effect should be attributed to iodide released from the iodopyrine, or a specific thiouracil-like action of the iodopyrine molecule.

\section{Localized Pretibial Myxoedema and its Treatment}

In a small proportion of cases of thyrotoxicosisperhaps about 3 per cent. of those with diffuse goitres (Trotter and Eden, 1942)-irregular swellings can be found in the skin of the lower legs. The most usual place to find them is on the anterior aspect, just above the ankles. Often they affect the back of the leg as well; sometimes the dorsum of the foot is involved and they may extend as high as the middle thigh. Usually there is no discomfort, the patient merely complaining of the unsightliness of the swelling; when small this generally passes unremarked by the patient. The surface 0 the skin over the swellings may be slightly pink oz occasionally pigmented or hairy. Their outlin\& and contour is irregular and the attachment of haif. follicles to deeper structures often gives a "pig $\overrightarrow{\text { " }}$ skin' appearance.

When one of these swellings is incised a viscous glairy fluid oozes out. Section of the affected skio shows' that the connective tissue elements in the deeper layers of the dermis are widely separated bo a homogeneous substance, which staining by the periodic-Schiff method, or with thionin-blue shows to be mucin. Hence the lesion is known as ' localized myxoedema,' using the latter word in it $\vec{s}$ literal sense of ' mucinous oedema.' Watson ang Pearce (1947) showed that the mucinous materis contained hyaluronic acid.

With only one or two exceptions pretibial myx oedema occurs only in patients who either have active thyrotoxicosis, or who have had it in the past. A common time for it to appear, or to bee్ come more marked, is during the first few month $\mathcal{S}^{\circ}$ after successful treatment of the thyrotoxicosis (whether by thyroidectomy, radio-iodine or ant $\overrightarrow{-}$ thyroid drugs). The affected patients are usualle somewhat older than the average run of cases of toxic diffuse goitre, and there is a relative excessof males. Almost always some of the eye signsoof thyrotoxicosis are present; not uncommo $\mathbb{Z}$; these are marked and may amount to malignan exophthalmos. Clubbing of the fingers has beet present in some cases.

In untreated cases the lesions on the legs tend to increase over a period of some months, and the remain stationary. In those cases which I have been able to observe over periods of 10 or 20 years there has been a very gradual tendency for the lesions to become smaller, and they may eventually disappear.

The only disability being cosmetic, treatment is only required in cases in which the lesions are. conspicuous. Thyroid hormones by mouth have no effect, and local injections of thyroxine were unsuccessful in one case. This is not surprising because the only connection between this condition and hypothyroidism lies in the word ' myxoedema, which is here used in its literal sense. I do not know of any reports of the local effects of any of the newer variants of the thyroid hormones. Locall injections of hyaluronidase provide a logical treatA ment since hyaluronic acid is a major constitueng of the plaques. The immediate effects are striking the lesions becoming softer in a few minutes, untis they pit on pressure. Unfortunately within couple of days they revert to their previous state so that repeated injections become necessary fo 5 an indefinite period. This is therefore not practical treatment. 


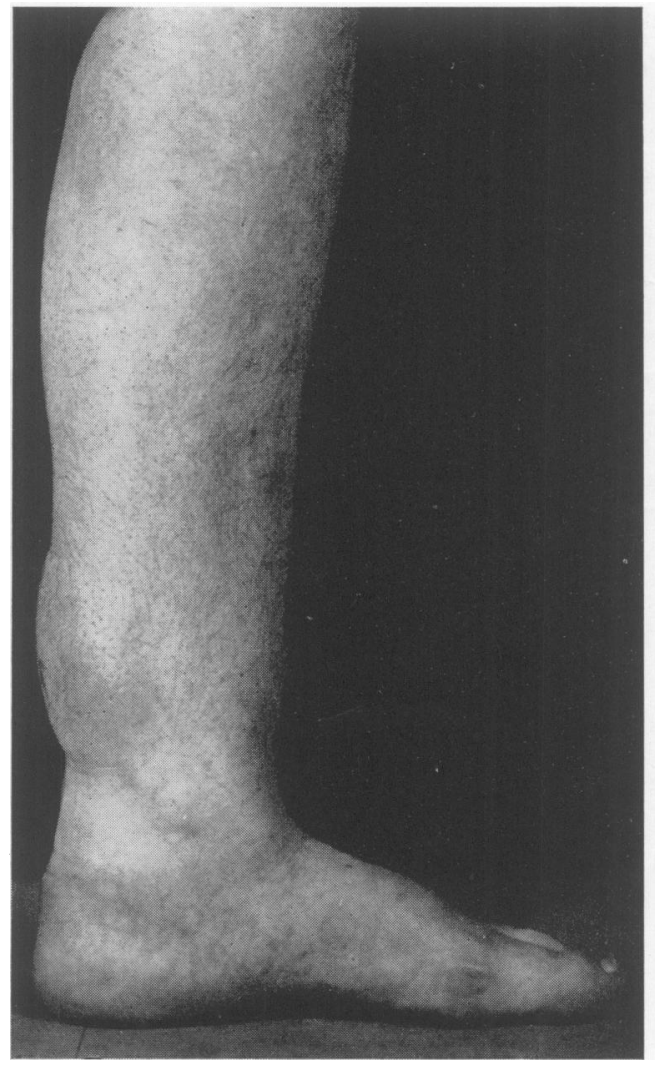

FIG. 4.-Left leg of a patient with localized myxoedema. A. Before treatment.

Inch and Rolland (1953) found that a combination of systemic cortisone with local injections of cortisone effectively reduced the size of the lesions. They felt, however, that the condition was not serious enough to justify the long-continued systemic administration of cortisone, and local injections by themselves were less effective. The addition of hyaluronidase to the suspension of cortisone did not improve the results. Zugerman (1954) treated one case with hydrocortisone by mouth, combined with local inunction of hydrocortisone ointment. The result was disappointing. I am not aware of any reports of the effects of actually injecting hydrocortisone into the lesions, but Dr. M. E. Morgans and I have tried this procedure in a single case; the immediate results were so satisfactory that they merit a brief note here, although the patient has not been observed for long enough for a final assessment. The patient was a woman of 37 , who had been under observation for thyrotoxicosis for three years. She had well-marked exophthalmos and lid-retraction, with slight limitation of lateral ocular movements.

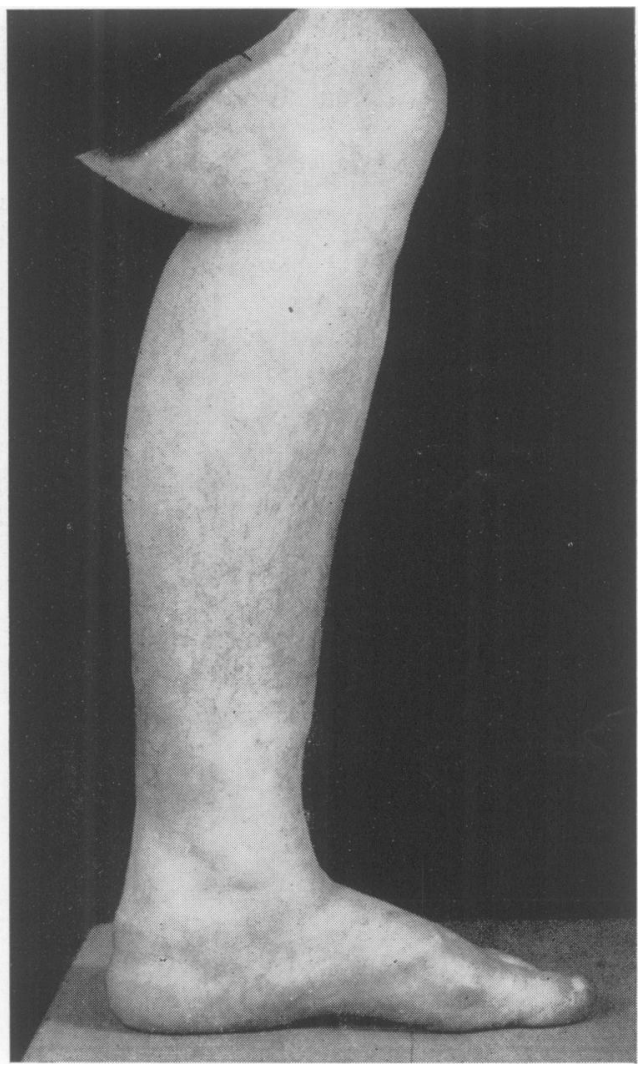

B. Seven weeks after the end of a series of hydrocortisone injections.

The degree of actual hyperthyroidism was slight and was controlled with potassium perchlorate. Localized myxoedema was first noticed three years after the patient's first attendance. Typical irregular swellings appeared, affecting both the front and the back of the lower half of both legs.

Two months after the lesions were first noticed, injections of hydrocortisone were started into the large swelling at the back of the right leg; $25 \mathrm{mg}$. of hydrocortisone acetate suspended in $1 \mathrm{ml}$. physiological saline were injected weekly. On each occasion the same volume of physiological saline was injected into a corresponding area of the left leg. After five weeks' treatment the swelling on the back of the right leg (originally the larger) had virtually disappeared, while the swelling on the back of the left leg was unchanged. This observation showed conclusively that hydrocortisone was effective, so the remaining swellings on the back and front of both legs were injected with hydrocortisone. After a total of 12 weeks treatment no visible swellings remained but small irregular thickenings were still palpable. After 
another seven weeks without further treatment these had decreased still further (Fig. 4). The improvement has been maintained during the subsequent three months.

Observations by Atkinson et al., (1956) lead us to hope that the effects of local hydrocortisone will last for a considerable time. They observed local cell destruction and the suppression of inflammatory reaction after the injection of hydrocortisone into normal skin. Crystals of hydrocortisone could still be identified in the skin seven to eight months later. It is not clear how hydrocortisone produces its effects in localized myxoedema so the treatment is quite empirical ; and of course further experience is required before it can be recommended with any confidence.

\section{BIBLIOGRAPHY}

STANBURY, J. B. and HEDGE, A. N. (1950), f. clin. Endocr., ro, I47I.

STANBURY, J. B., OHELA, K. and PITT-RIVERS, R. (1955a), Ibid., $15,54$.

STANBURY, J. B., KASSENAAR, A. A. H., MEIJER, J. W. A. and TERPSTRA, J. (1955b), Ibid., 15, 1216.
QUERIDO, A., STANBURY, J. B., KASSENAAR, A. A. H. a? MEIJER, J. W. A. (1956), Ibid., 16, 1096.

McGIRR, E. M. and HUTCHISON, J. H. (1953), Lancet, i, II fि. McGIRR, E. M., HUTCHISON, J. H. and CLEMENT, W. $\overrightarrow{\bar{F}}$ (I956), Ibid., ii, 906.

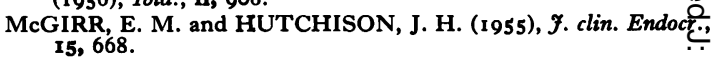

GILLILAND, I. C. and STRUDWICK, J. I. (1956), Brit. med. i, 378 .

BARKER, M. H. (1936), Ұ. Amer. med. Ass., ro6, 762.

BARKER, M. H., LINDBERG, H. A. and WALD, M. H. (194 f. Amer. med. Ass., II7, 1591 .

BULL, G. M. and FRASER, R. (1950), Lancet, i, 851 .

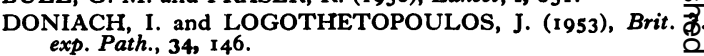

EDWARDS, D. A. W., ROWLANDS, E. N. and TROTTEB, W. R. (1954), Lancet, ii, 105 I.

MORGANS, M. E. and TROTTER, W. R. (1955), Lancet, ii, 16 MORGANS, M. E. and TROTTER, W. R. (1953), Lancet, ii, 1335. HYDOVITZ, J. D. and ROSE, R. (1956), F. clin. Endocr., 16, I 109. TROTTER, W. R. and EDEN, K. C. (1942), Quart. F. Med., 可

WATSON, E. M. and PEARCE, R. H. (1947), Amer. F. clin. Pa茾

INCH, R. S. M. D. and ROLLAND, C. F. (1953), Lancet, ii, $12 \frac{3}{30}$; ZUGERMAN, I. (1954), New Engl. F. Med., 25I, 973. ATKINSON, W. B., SUSKIND, R. R. and GOLDMAN, $\omega_{\infty}$
(I956), Arch. Path., 62, 8.

KRISS, J. P., CARNES, W. H. and GROSS, R. T. (1955), F. Amer med. Ass., 55, 117 .

\section{ANAESTHETICS}

(Special number of Postgraduate Medical Journal, September 1955)

Price: 3s. 9d. post free

THE MODERN VIEW OF ANAESTHESIA

G. S. W. Organe, M.D., D.A., F.F.A.R.C.S.

THE PRODUCTION OF

UNCONSCIOUSNESS

B. G. B. Lucas, D.A., F.F.A.R.C.S.

ANALGESIA

J. B. Wyman, M.B.E., D.A., F.F.A.R.C.S.

MUSCLE RELAXATION IN SURGERY

Angus Smith, F.F.A.R.C.S.

CONTROL OF THE BLOOD PRESSURE AND CONTROLLED HYPOTENSION

C. F. Scurr, M.V.O., D.A., F.F.A.R.C.S.
CHLORPROMAZINE AND ALLIED SUBSTANCES

John Beard, M.D., D.A., F.F.A.R.C.S., D.C.H.

CONTROLLED HYPOTHERMIA

E. J. Delorme, M.D., F.R.C.S.(C.)

MANAGEMENT OF THE APNOEIC

PATIENT

Ronald Woolmer, D.A., F.F.A.R.C.S.

THE USE OF ANTIDOTES IN

ANAESTHESIA

B. A. Sellick, D.A., F.F.A.R.C.S.

Published by

THE FELLOWSHIP OF POSTGRADUATE MEDICINE

60, Portland Place, London, W.1 